\title{
Vitamin D Does Not Have Any Impact on Ovarian Reserve Markers in Infertile Women
}

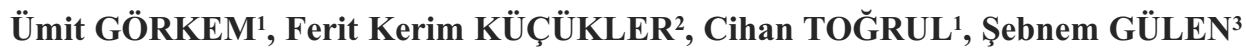 \\ Çorum, Turkey
}

\begin{abstract}
OBJECTIVE: To evaluate the potential role of vitamin D on ovarian reserve markers in infertile women with different reserve patterns.

STUDY DESIGN: This prospective cross-sectional study included the infertile women attending the Hitit University Hospital. The initial examination included the measurements of waist circumference and hip circumference, body mass index, and waist/hip ratio. A total of 171 women were divided into three groups according to ovarian reserve patterns: (i) adequate ovarian reserve pattern ( $A O R, n=77$ ), (ii) high ovarian reserve pattern (polycystic ovarian syndrome, $n=62$ ), and (iii) diminished ovarian reserve pattern (DOR, $n=32$ ). The serum estradiol (E2), follicle stimulating hormone, total testosterone, 17-hydroxyprogesterone $(17(\mathrm{OH}) \mathrm{P})$, dehydroepiandrosterone sulfate, anti-mullerian hormone, and hydroxycholecalciferol $(25(\mathrm{OH}) \mathrm{D})$ levels were analyzed.
\end{abstract}

RESULTS: No significant difference between three different groups was detected in terms of body mass index, waist circumference, hip circumference, waist/hip ratio, E2 and 17OHP levels ( $p>0.05$, for all). One-hundred-sixty-nine (98.2\%) women in all groups had vitamin D concentration below $30 \mathrm{ng} / \mathrm{mL}$ as a cut-off value. The circulating $25(\mathrm{OH}) \mathrm{D}$ levels did not show a significant difference between all ovarian reserve groups $(p=0.804)$. No correlation between $25(\mathrm{OH}) \mathrm{D}$ and anti-mullerian hormone levels was documented in women with AOR, polycystic ovarian syndrome and DOR patterns $(r=-0.099 p=0.393$, $r=0.034 p=0.794$ and $r=0.157 p=0.390$ respectively). $25(\mathrm{OH}) \mathrm{D}$ levels were significantly correlated with body mass index, waist circumference and hip circumference parameters only in AOR group ( $r=-0.355$ $p=0.002, r=-0.305 p=0.007$ and $r=-0.322 p=0.004$ respectively).

CONCLUSIONS: There is no association between $25(\mathrm{OH}) \mathrm{D}$ and ovarian reserve markers. $25(\mathrm{OH}) \mathrm{D}$ levels were significantly correlated with body mass index, waist circumference and hip circumference parameters only in AOR group.

Keywords: Vitamin D, $25(\mathrm{OH})$ D, Ovarian reserve, Anti-mullerian hormon

Gynecol Obstet Reprod Med 2017;23(2):79-83

\section{Introduction}

Vitamin D refers to a fat-soluble secosteroid responsible for regulating calcium, iron, magnesium, phosphate and zinc metabolisms. Two main forms of vitamin D play a crucial role in

${ }^{1}$ Hitit University Faculty of Medicine Department of Obstetrics and Gynecology, and 'Endocrinology, Çorum

${ }^{3}$ Ufuk University Faculty of Medicine Department of Physiology, Ankara Address of Correspondence: Ümit Görkem Hitit University Faculty of Medicine Department of Obstetrics and Gynecology Çorum, Turkey drumitgorkem@hotmail.com

Submitted for Publication: $\quad$ 08.02.2017 Accepted for Publication: $\quad 23.02 .2017$

\begin{tabular}{|c|c|}
\hline & Access this article online \\
\hline $\begin{array}{c}\text { Quick Response Code: } \\
\text { Website: www.gorm.com.tr }\end{array}$ \\
\cline { 2 - 2 }
\end{tabular}

How to cite this article: Görkem Ü. Küçükler FK. Toğrul C. Gülen Ş. Vitamin $D$ Does Not Have Any Impact on Ovarian Reserve Markers in Infertile Women. Gynecol Obstet Reprod Med 2017;23(2):79-83 humans, i.e. vitamin D2 (ergocalciferol) and D3 (cholecalciferol) (1). The serum levels of hydroxycholecalciferol $(25(\mathrm{OH})$ D) as a metabolite of vitamin $\mathrm{D}$ are considered the best indicator of vitamin D status due to its easy measurement and long half-life in circulation (2). The global epidemic of vitamin D deficiency has recognized the notion that vitamin $\mathrm{D}$ possesses a much wider range of actions that include pro-differentiation, anti-proliferation, pro-apoptosis, immunosuppression, and anti-inflammation $(1,3,4)$. The biological actions of vitamin D are mediated through vitamin D receptors (5). Vitamin D receptors has been identified not only in calcium regulating tissues (intestines, skeleton and parathyroid glands) and immune system ( $\mathrm{T}$ and $\mathrm{B}$ cells, macrophages and monocytes), but also in various reproductive organs, such as ovaries, uterus, placenta, testis, hypothalamus, and pituitary gland $(1,6,7)$.

Currently available data identify vitamin $\mathrm{D}$ as a vital role in the reproductive processes (8). Recently, vitamin D has been shown to be a target for anti-mullerian hormone (AMH) actions $(9,10)$. Anti-mullerian hormone is a glycoprotein synthesized by the granulosa cells of principally small antral fol- 
licles in the ovary. Anti-mullerian hormone (AMH) has a crucial role in maintaining ovarian reserve and modifying the follicle response to gonadotropins (11). Over the past decades, $\mathrm{AMH}$ is considered as one of the most reliable markers for ovarian reserve (12). Accumulating evidence in the literature suggests that vitamin D has been involved in ovarian reserve status, in vitro fertilization (IVF) outcomes, features of polycystic ovarian syndrome (PCOS) and endometriosis. These observations provide new aspects in the pathogenesis of infertility (13). Thus, we conducted the present study to evaluate the potential role of vitamin D on ovarian reserve markers in infertile women with different ovarian reserve patterns.

\section{Material and Method}

\section{Study population}

This prospective cross-sectional study analyzed the participant's data obtained as a part of their fertility assessments between December 2015 and February 2016 at the Hitit University Hospital in Corum, Turkey. The ethics committee of Ankara Numune Hospital approved the study that was in accordance with the Declaration of Helsinki 2013 Brazil version (20796219-724.087). The written informed consents were collected from all participant women before inclusion in the study. It was paid attention that the participant women demonstrated similar wearing styles. The inclusion criteria were accepted as less than 45 years of age and no history of menopause, premature ovarian failure, pelvic surgery, endometriosis, ovarian masses, smoking, current use of medications known to affect reproductive functions and vitamin D metabolism, chronic systemic diseases and hyperprolactinemia. The initial physical examination included the measurements of weight, height, waist circumference (WC) and hip circumference (HC), body mass index (BMI), and waist/hip ratio (WHR). Body mass index (BMI) was calculated by dividing the weight in kilogram by the height in meters squared. Waist circumference (WC) was measured at the midpoint of the lowest margin of $12^{\text {th }}$ rib and the lateral iliac crest, during normal expiration. Hip circumference (HC) was measured at the maximum extension of the major trochanters. All anthropometric measurements were done with the same scale and by the same observer. Additionally, the antral follicle count (AFC) was detected using a Toshiba Xario 100 (Toshiba Medical Systems Corporation, Nasu, Japan) with a 7.5-MHz vaginal transducer by the same clinician in the early follicular phase on days 2-5 of the menstrual cycle.

A total of 171 participants who met the inclusion criteria were recruited for the study. The participant women were divided into three groups in relation with their ovarian reserve patterns: (i) women with adequate ovarian reserve pattern (AOR, n=77), (ii) women with high ovarian reserve pattern (PCOS, $\mathrm{n}=62$ ), and (iii) women with diminished ovarian reserve pattern (DOR, $n=32$ ). Polycystic ovarian syndrome was diagnosed in relation with the opinion of American Association of Clinical Endocrinologists (AACE); American
College of Endocrinology (ACE); Androgen Excess and PCOS Society (AES), American Association of Clinical Endocrinologists, American College of Endocrinology, and Androgen excess and PCOS Society (2015), when two of the following three features were present: chronic anovulation, hyperandrogenism (clinical or biological) and polycystic ovaries, presence of $\geq$ at least 25 follicles measuring 2-9 mm in diameter and/or ovarian volume $>10 \mathrm{~cm}^{3}$ ) (14). The diminished ovarian reserve was defined as $<7$ antral follicles in total, based on the opinion of American College of Obstetricians and Gynecologists (15).

\section{Data collection and assays}

The blood samples of participants were obtained from antecubital vein after an overnight fasting between $08 \mathrm{AM}$ and 10 AM in the early follicular phase on days 2 to 5 . The blood samples were collected into $5 \mathrm{~mL}$ serum separator tubes (BD Vacutainer, Becton Dickinson, New Jersey, USA). The samples allowed to clot completely at room temperature, and then centrifuged within $30 \mathrm{~min}$ at $3000 \mathrm{rpm}$ for 20 minutes. The serums were analyzed on a daily basis for estradiol (E2), follicle stimulating hormone (FSH), total testosterone (TT), 17-hydroxyprogesterone $(17(\mathrm{OH}) \mathrm{P})$ and dehydroepiandrosterone sulfate (DHEAS) with an electrochemiluminescence immunoassay (ECLIA) method using an auto analyzer (Cobas 6000, E 601 Roche Diagnostics, GmbH, Mannheim, Germany). To obtain minimal fluctuations in samples, serum for AMH measurements was frozen at $-20{ }^{\circ} \mathrm{C}$ within 2 hours for a maximum of 7 days and then analyzed. All analyses of AMH samples were also performed on a weekly basis by the ECLIA method using an auto analyzer (Cobas 6000, E 601 Roche Diagnostics, GmbH, Mannheim, Germany). The serum 25(OH) D levels were also measured by liquid chromatography tandem mass spectrometry (Waters Quattro Premier mass spectrometer Milford, Massachusetts, USA). Vitamin D deficiency or insufficiency are defined as vitamin D levels $<20 \mathrm{ng} / \mathrm{mL}$, or 20 to $29.9 \mathrm{ng} / \mathrm{mL}$, respectively. Then, the comparisons and correlations of all data were performed in all ovarian reserve groups.

\section{Statistical analysis}

All analyses were performed using SPSS (Statistical Packages for The Social Sciences) software version 21 (SPSS Inc. Chicago, USA). The continuous variables were first evaluated for normality of statistical distribution by Shapiro-Wilk test. As the continuous variables were normally distributed, parametric methods were used to perform statistical analyses. Descriptive statistics were expressed as means (standard deviation) and number (percentage \%). The differences between the group averages were tested by one-way variant analysis. LSD test, as a kind of the post hoc analysis, was used to detect the origin of differences. Spearman's correlation analysis was performed to test any continuous relationship between $25(\mathrm{OH}) \mathrm{D}$ and study variables. A p value of less than 0.05 and a confidence interval of $95 \%$ were considered as statistically significant. 


\section{Results}

The comparisons of baseline characteristics and hormonal parameters between AOR, PCOS and DOR patterns are shown in table 1. One-hundred-seventy-one women between the ages 18-42 were recruited for this study. The mean age of the overall study population was 30.2 years. The mean ages of all ovarian reserve groups significantly differed from each other. As expected, women with DOR had the highest mean age $(\mathrm{p}<0.001)$. Likewise, no statistically significant difference between three different groups was detected in terms of BMI, WC, HC, WHR, E2 and 17OHP levels ( $>0.05$, for all). Whereas the FSH levels in DOR group were significantly elevated than in other groups $(\mathrm{p}<0.001)$, the highest LH levels were detected in women with PCOS pattern $(\mathrm{p}<0.001)$. The women with PCOS pattern possessed the most elevated TT and DHEAS levels compared to women with AOR and PCOS ( $\mathrm{p}=0.015$ and $\mathrm{p}<0.001$ respectively). We also demonstrated that DOR group had the lowest AMH concentrations $(p<0.001)$. One-hundred-sixty-nine $(98.2 \%)$ women with all ovarian reserve groups possessed vitamin D concentration below $30 \mathrm{ng} / \mathrm{mL}$ as a cutoff value. Besides, the circulating $25(\mathrm{OH}) \mathrm{D}$ levels did not show a significant difference between all ovarian reserve groups $(\mathrm{p}=0.804)$.

Table 1: The comparisons of baseline characteristics and hormonal parameters between different ovarian reserve patterns

\begin{tabular}{|c|c|c|c|c|c|c|c|}
\hline & \multicolumn{2}{|c|}{$\begin{array}{c}\text { Adequate } \\
\text { Ovarian } \\
\text { Reserve } \\
\text { Group (AOR) } \\
(n=77,45.0 \%)\end{array}$} & \multicolumn{2}{|c|}{$\begin{array}{c}\text { High } \\
\text { Ovarian } \\
\text { Reserve } \\
\text { Group (PCOS) } \\
(\mathrm{n}=62,36.3 \%)\end{array}$} & \multicolumn{2}{|c|}{$\begin{array}{c}\text { Diminished } \\
\text { Ovarian } \\
\text { Reserve } \\
\text { Group (DOR) } \\
(\mathrm{n}=32,18.7 \%)\end{array}$} & \\
\hline & Mean & SD & Mean & SD & Mean & SD & \\
\hline Age (year) & 30.0 & 5.9 & 27.6 & 4.7 & 36.0 & 4.3 & $0.000^{*}$ \\
\hline BMI $\left(\mathrm{kg} / \mathrm{m}^{2}\right)$ & 26.4 & 5.3 & 26.0 & 4.9 & 26.3 & 4.1 & 0.881 \\
\hline WC $(\mathrm{cm})$ & 89.5 & 11.6 & 90.0 & 15.5 & 90.4 & 10.2 & 0.937 \\
\hline $\mathrm{HC}(\mathrm{cm})$ & 105.3 & 10.6 & 104.7 & 10.7 & 105.3 & 7.8 & 0.914 \\
\hline WHR & 0.9 & 0.1 & 0.9 & 0.1 & 0.9 & 0.1 & 0.778 \\
\hline E2 $(p g / m L)$ & 44.3 & 21.7 & 41.5 & 32.9 & 53.3 & 33.5 & 0.159 \\
\hline FSH (IU/L) & 7.0 & 1.5 & 6.3 & 2.0 & 9.4 & 2.8 & $0.000^{*}$ \\
\hline LH (IU/L) & 5.8 & 2.1 & 7.6 & 3.5 & 6.4 & 2.8 & $0.001^{*}$ \\
\hline TT (ng/dL) & 26.6 & 29.4 & 30.5 & 14.5 & 16.4 & 10.5 & $0.015^{*}$ \\
\hline $17(\mathrm{OH}) \mathrm{P}(\mathrm{ng} / \mathrm{dL})$ & 1.4 & 5.5 & 1.1 & 1.5 & 1.3 & 3.6 & 0.870 \\
\hline DHEAS (mcg/dL) & 212.7 & 85.7 & 253.2 & 110.9 & 172.7 & 78.5 & $0.000^{*}$ \\
\hline $\mathrm{AMH}(\mathrm{ng} / \mathrm{dL})$ & 3.3 & 2.0 & 7.3 & 4.6 & 0.8 & 0.5 & $0.000^{*}$ \\
\hline $25(\mathrm{OH}) \mathrm{D}(\mathrm{ng} / \mathrm{mL})$ & 8.9 & 5.6 & 8.5 & 6.6 & 9.3 & 6.6 & 0.804 \\
\hline
\end{tabular}

SD: Standard deviation, BMI: Body mass index, WC: Waist circumference, HC: Hip circumference, WHR: Waist hip circumference ratio, E2: Estradiol, FSH: Follicle stimulating hormone, LH: Luteinizing hormone, TT: Total testosterone, 17(OH)P: 17-hydroxyprogesterone, DHEAS: Dehydroepiandrosterone sulfate, 25(OH)D: 25-hydroxyvitamin D, AMH: Antimullerian hormone, 25(OH)D: 25-hydroxycholecalciferol. ${ }^{*} p$-values indicate statistically significant $(p<0.05)$.

The relationships between serum $25(\mathrm{OH})$ D levels and other study parameters were analyzed by Pearson's correlation, as demonstrated in table 2. No correlation between $25(\mathrm{OH}) \mathrm{D}$ and AMH levels was documented in women with AOR, PCOS and DOR patterns $(r=-0.099 \mathrm{p}=0.393, \mathrm{r}=0.034$ $\mathrm{p}=0.794$ and $\mathrm{r}=0.157 \mathrm{p}=0.390$ respectively). There was a positive correlation between $25(\mathrm{OH}) \mathrm{D}$ and FSH levels in AOR pattern $(\mathrm{r}=0.285 \mathrm{p}=0.012)$. However, this correlation was not demonstrated in PCOS and DOR groups $(\mathrm{r}=-0.101 \mathrm{p}=0.435$ and $\mathrm{r}=0.180 \mathrm{p}=0.323$ respectively). In addition, there was no correlation between $25(\mathrm{OH}) \mathrm{D}$ and $\mathrm{LH}$, TT, DHEAS, WHR parameters in three different groups. Interestingly, 25(OH) D levels were significantly correlated with BMI, WC and $\mathrm{HC}$ parameters only in AOR group $(\mathrm{r}=-0.355 \mathrm{p}=0.002$, $\mathrm{r}=-0.305 \mathrm{p}=0.007$ and $\mathrm{r}=-0.322 \mathrm{p}=0.004$ respectively). Furthermore, the correlations of $25(\mathrm{OH})$ D levels with BMI, WC and $\mathrm{HC}$ were not detected in PCOS and DOR groups.

Table 2: The relationships between serum $25(\mathrm{OH})$ $D$ levels and other study parameters in women with between different ovarian reserve patterns

\begin{tabular}{|c|c|c|c|c|}
\hline & & \begin{tabular}{|l|} 
Adequate \\
Ovarian \\
Reserve \\
Group \\
(AOR) \\
$(n=77$, \\
$45.0 \%)$
\end{tabular} & $\begin{array}{l}\text { High } \\
\text { Ovarian } \\
\text { Reserve } \\
\text { Group } \\
\text { (PCOS) } \\
(\mathrm{n}=62 \text {, } \\
36.3 \%)\end{array}$ & $\begin{array}{l}\text { Diminishe } \\
\text { d Ovarian } \\
\text { Reserve } \\
\text { Group } \\
\text { (DOR) } \\
(\mathrm{n}=32, \\
18.7 \%)\end{array}$ \\
\hline \multirow{2}{*}{$\begin{array}{l}\text { Age } \\
\text { (year) }\end{array}$} & $r$ & 0.098 & -0.067 & 0.075 \\
\hline & $p$ & 0.395 & 0.607 & 0.684 \\
\hline \multirow{2}{*}{$\begin{array}{l}\mathrm{BMI} \\
\left(\mathrm{kg} / \mathrm{m}^{2}\right)\end{array}$} & $r$ & $-0.355^{*}$ & -0.141 & -0.226 \\
\hline & $p$ & 0.002 & 0.275 & 0.215 \\
\hline \multirow{2}{*}{$W C(\mathrm{~cm})$} & $r$ & $-0.305^{\star}$ & -0.137 & -0.165 \\
\hline & $p$ & 0.007 & 0.290 & 0.368 \\
\hline \multirow{2}{*}{$\mathrm{HC}(\mathrm{cm})$} & $r$ & $-0.322^{*}$ & -0.214 & -0.207 \\
\hline & $p$ & 0.004 & 0.095 & 0.255 \\
\hline \multirow{2}{*}{ WHR } & $r$ & -0.086 & -0.008 & -0.049 \\
\hline & $p$ & 0.456 & 0.949 & 0.788 \\
\hline \multirow{2}{*}{$\begin{array}{l}\text { E2 } \\
(\mathrm{pg} / \mathrm{mL})\end{array}$} & $r$ & 0.119 & 0.040 & 0.280 \\
\hline & $p$ & 0.304 & 0.760 & 0.121 \\
\hline \multirow{2}{*}{$\begin{array}{l}\text { FSH } \\
(\mathrm{IU} / \mathrm{L})\end{array}$} & $r$ & $0.285^{*}$ & -0.101 & 0.180 \\
\hline & $p$ & 0.012 & 0.435 & 0.323 \\
\hline \multirow{2}{*}{$\begin{array}{l}\mathrm{LH} \\
(\mathrm{IU} / \mathrm{L})\end{array}$} & $r$ & 0.127 & 0.079 & 0.349 \\
\hline & $p$ & 0.271 & 0.540 & 0.050 \\
\hline \multirow{2}{*}{$\begin{array}{l}\text { TT } \\
(\mathrm{ng} / \mathrm{dL})\end{array}$} & $r$ & -0.091 & -0.088 & -0.001 \\
\hline & $p$ & 0.432 & 0.497 & 0.994 \\
\hline \multirow{2}{*}{$\begin{array}{l}17(\mathrm{OH}) \mathrm{P} \\
(\mathrm{ng} / \mathrm{dL})\end{array}$} & $r$ & 0.009 & $0.342^{*}$ & -0.055 \\
\hline & $p$ & 0.938 & 0.007 & 0.764 \\
\hline \multirow{2}{*}{$\begin{array}{l}\text { DHEAS } \\
(\mathrm{mcg} / \mathrm{dL})\end{array}$} & $r$ & -0.119 & 0.031 & -0.032 \\
\hline & $p$ & 0.304 & 0.809 & 0.863 \\
\hline \multirow{2}{*}{$\begin{array}{l}\text { AMH } \\
(\mathrm{ng} / \mathrm{dL})\end{array}$} & $r$ & -0.099 & 0.034 & 0.157 \\
\hline & $p$ & 0.393 & 0.794 & 0.390 \\
\hline
\end{tabular}

Abbreviations: BMI: Body mass index, WC: Waist circumference, HC: Hip circumference, WHR: Waist hip circumference ratio, E2: Estradiol, FSH: Follicle stimulating hormone, LH: Luteinizing hormone, TT: Total testosterone, 17(OH)P: 17-hydroxyprogesterone, DHEAS: Dehydroepiandrosterone sulfate, 25(OH)D: 25-hydroxyvitamin D, AMH: Antimullerian hormone.

${ }^{*} p$-values indicate statistically significant $(p<0.05)$. 


\section{Discussion}

This study focused on the associations of $25(\mathrm{OH})$ D levels with various kinds of ovarian reserve markers and other hormones. We could not observe any correlation between serum $25(\mathrm{OH}) \mathrm{D}$ and hormonal profile in three different patterns of ovarian reserve. However, our findings suggested the correlations between serum $25(\mathrm{OH}) \mathrm{D}$ concentration and increased body parameters, including BMI, WC and HC only in AOR group.

In the existing literature, there are conflicting studies about the influence of vitamin $\mathrm{D}$ on $\mathrm{AMH}$ as an ovarian reserve marker. Previous studies were investigated the relationship between vitamin D and ovarian reserve status. Although our results do not agree with these studies, human studies have reported positive correlations between serum 25(OH) D and AMH levels $(11,16,17)$. Merhi et al. found a weak negative association between vitamin D and AMH levels in women under 35 years of age and a weak positive relationship above 40 years of age (10). However, serum AMH levels were mostly very low and even sometimes non-measurable as expected in such women. Dennis et al. conducted a study, which was one of first studies reporting that vitamin D might exert a positive impact on AMH production (16). Nevertheless, the study population was small and did not consider the ovarian status. A study by Jukic et al. examined the relationship of vitamin D status with FSH. The authors noted a negative correlation between serum vitamin D levels and urinary FSH levels. Thus, they claimed that lower vitamin D levels might have an effect on ovarian reserve (18). Contrarily, Irani et al. conducted a prospective study in which was postulated that calcitriol supplementation normalized serum AMH levels in vitamin D deficient premenopausal women. However, they did not demonstrate any significant change in serum AMH levels (17). We failed to demonstrate any relationship between $25(\mathrm{OH}) \mathrm{D}$ and AMH levels in current study. Moreover, vitamin D level did not correlate with other ovarian reserve markers.

The prevalence rates of vitamin $\mathrm{D}$ deficiency is range between 10 and $60 \%$ throughout the world, although the definition of vitamin D deficiency remains controversial (19). Vitamin D deficiency and insufficiency are present in $74.9 \%$ and $13.8 \%$ of the Turkish population in a study by Hekimsoy (20). In our infertile population, $98.2 \%$ of the women had a vitamin D deficiency. This data is in agreement with another study reporting high prevalence of vitamin D deficiency in infertile women (21).

The effect of testosterone $(\mathrm{T})$ on male reproduction has been intensively studied, and considerable evidence supports the influence of vitamin D on semen quality (22). However, few studies have focused on the effects of testosterone in women, and the relationship between $\mathrm{T}$ and vitamin $\mathrm{D}$ levels has been investigated in a little quantities. Chang et al. supposed that the serum vitamin D level was not associated the cir- culating ovarian reserve markers (AMH, FSH, total antral follicle count, ovarian volume). The authors also noted a positive correlation between serum vitamin D and testosterone levels suggesting vitamin D may increase fertility through modulating of androgen activity (23). However, we could not demonstrate such a relationship between vitamin D and androgens.

Though decreased vitamin D levels have been reported in women with premature ovarian failure (24), this does not appear to be a causal relationship because a recent study reported that vitamin D levels were similar in early and late menopause (25). In a study from Turkey, 25(OH) D levels did not differ between the POF group and the control group. The authors concluded that vitamin $\mathrm{D}$ did not have a role in etiology of POF (26).

In parallel with our findings, in a large retrospective study by Pearce et al., serum vitamin D levels appeared to be unrelated to AMH levels in 340 predominately-Caucasian women. The women with different ovarian reserve status and corresponding AMH levels (PCOS, diminished ovarian reserve and fertile controls) had no significant difference in serum vitamin D levels (27). Furthermore, Nurses' Health Study II reported that vitamin D did not appear to have a major effect on AMH production (28), which is consistent with our observations.

Certain limitations to be mentioned exist in the present study. Firstly, the women included in the study population were infertile rather than the normal ones. Secondly, because our study included a relatively small number of infertile population with low mean level of vitamin $\mathrm{D}$, it is insufficient to generalize to all women or to establish an optimal threshold. Lastly, we could not determine whether a causal relationship exists between vitamin D level and increased body size parameters.

\section{Conclusions}

Most of the studies favoring the positive effect of vitamin $\mathrm{D}$ on $\mathrm{AMH}$ production and secretion used markers of ovarian reserve/function rather than pregnancy rates as fertility outcome, which limits translational significance of the findings. In the existing literature, vitamin D seems to play a role in ovarian function functions. Taken all together, our findings suggest that there is no association between $25(\mathrm{OH}) \mathrm{D}$ and ovarian reserve markers. $25(\mathrm{OH}) \mathrm{D}$ levels were significantly correlated with BMI, WC and HC parameters only in AOR group. However, the correlations of $25(\mathrm{OH}) \mathrm{D}$ levels with BMI, WC and HC were disappeared in PCOS and DOR groups. The devoid of association between $17(\mathrm{OH}) \mathrm{D}$ and anthropometric measurements in PCOS and DOR ovarian reserve groups warrant further large prospective investigations.

\section{References}

1. Holick MF. Vitamin D deficiency. N Engl J Med 2007; 357(3):266-81.

2. Vieth R, Vitamin D supplementation, 25-hydroxyvitamin D concentrations, and safety, Am J Clin Nutr 1999;69(5): 
$842-56$.

3. Liu PT, Stenger S, Li H, Wenzel L, Tan BH, Krutzik SR, et al. Toll-like receptor triggering of a vitamin D-mediated human antimicrobial response. Science 2006;311(5768): 1770-3.

4. Mitri J, Dawson-Hughes B, Hu FB, Pittas AG. Effects of vitamin $\mathrm{D}$ and calcium supplementation on pancreatic \{beta\} cell function, insulin sensitivity, and glycemia in adults at high risk of diabetes: the Calcium and Vitamin D for Diabetes Mellitus randomized controlled trial. Am J Clin Nut 2011;94(2):486-94.

5. Halloran BP, DeLuca HF. Effect of vitamin D deficiency on fertility and reproductive capacity in the female rat. $\mathrm{J}$ Nutr 1980;110(8):157380.

6. Kinuta K, Tanaka H, Moriwake T, Aya K, Kato S, Seino Y. Vitamin D is an important factor in estrogen biosynthesis of both female and male gonads. Endocrinology 2000; 141(4):1317-24.

7. Harkness LS, Bonny AE. Calcium and vitamin D status in the adolescent: key roles for bone, body weight, glucose tolerance, and estrogen biosynthesis. J Pediatr Adolesc Gynecol 2005;18(5):305-11.

8. Ozkan S, Jindal S, Greenseid K, Shu J, Zeitlian G, Hickmon $\mathrm{C}$, et al. Replete vitamin D stores predict reproductive success following in vitro fertilization. Fertil Steril 2010;94(4):1314-9.

9. Irani M, Merhi Z. Role of vitamin D in ovarian physiology and its implication in reproduction: a systematic review. Fertil Steril 2014;102(2):460-8.e3.

10. Merhi ZO, Seifer DB, Weedon J, Adeyemi O, Holman S, Anastos K, et al. Circulating vitamin D correlates with serum antimullerian hormone levels in late-reproductive aged women: Women's Interagency HIV Study. Fertil Steril 2012;98(1):228-34.

11. Dewailly DCY, Andersen A, Balen F, Broekmans N, Dilaver R, Fanchin G, et al. The physiology and clinical utility of anti-Mullerian hormone in women. Hum Reprod Update 2014;20(3):370-85.

12. Seifer DB, Scott RT Jr, Bergh PA, Abrogast LK, Friedman CI, Mack CK, et al. Women with declining ovarian reserve may demonstrate a decrease in day 3 serum inhibin $\mathrm{B}$ before a rise in day 3 follicle-stimulating hormone. Fertil Steril 1999;72(1):63-5.

13. Schmidt L. Social and psychological consequences of infertility and assisted reproduction- what are the research priorities? Hum Fertil (Camb) 2009;12(1):14-20.

14. Goodman NF, Cobin RH, Futterweit W, Glueck JS, Legro RS, Carmina E, American Association of Clinical Endocrinologists; American Association of Clinical Endocrinologists; American College of Endocrinology; Androgen Excess and PCOS Society. American Association of Clinical Endocrinologists, American College of Endocrinology, and Androgen excess and PCOS Society Disease State
Clinical Review: Guide to the best practices in the evaluation and treatment of polycystic ovary syndrome-Part 1 . Endocr Pract 2015;21(11):1291-300.

15. Ovarian reserve testing. Committee Opinion No. 618. American College of Obstetricians and Gynecologists. Obstet Gynecol 2015;125(1):268-73.

16. Dennis NA, Houghton LA, Jones GT, van Rij AM, Morgan K, McLennan IS. The level of serum anti-mullerian hormone correlates with vitamin D status in men and women but not in boys. J Clin Endocrinol Metab 2012; 97(7):2450-5.

17. Irani M, Minkoff H, Seifer DB, Merhi Z. Vitamin D increases serum levels of the soluble receptor for advanced glycation end products in women with PCOS. J Clin Endocrinol Metab 2014;99(5):E886-90

18. Jukic AMZ, Steiner AZ, Baird DD. Association between serum 25-hydroxyvitamin $\mathrm{D}$ and ovarian reserve in premenopausal women. Menopause 2015;22(3):312-6.

19. Prentice A. Vitamin D deficiency: a global perspective. Nutr Rev 2008;66(10 Suppl 2):153-64.

20. Hekimsoy Z, Dinç G, Kafesçiler S, Onur E, Güvenç Y, Pala T, et al. Vitamin D status among adults in the Aegean region of Turkey. BMC Public Health 2010;10:782.

21. Pagliardini L, Vigano P, Molgora M, Persico P, Salonia A, Vailati SH, et al. High prevalence of vitamin D deficiency in infertile women referring for assisted reproduction. Nutrients 2015;7(12):9972-84.

22. Blomberg Jensen M. Vitamin D metabolism, sex hormones, and male reproductive function. Reproduction 2012;144(2):135-52.

23. Chang EM, Kim YS, Won HJ, Yoon TK, Lee WS Association between sex steroids, ovarian reserve, and vitamin D levels in healthy nonobese women. J Clin Endocrinol Metab 2014;99(7):2526-32

24. Kebapcilar AG, Kulaksizoglu M, Kebapcilar L, Gonen MS, Unlü A, Topcu A, et al. Is there a link between premature ovarian failure and serum concentrations of vitamin D, zinc, and copper? Menopause 2013;20(1):94-99.

25. Lee MK, Yoon BK, Chung HY, Park HM. The serum vitamin D nutritional status and its relationship with skeletal status in Korean postmenopausal women. Obstet Gynecol Sci 2011;54(3):241-6

26. Ersoy E, Ersoy AO, Yildirim G, Buyukkagnici U, Tokmak A, Yilmaz N. Vitamin D levels in patients with premature ovarian failure. Ginekol Pol 2016;87(1):32-6

27. Pearce K, Gleeson K, Tremellen K. Serum anti-Mullerian hormone production is not correlated with seasonal fluctuations of vitamin D status in ovulatory or PCOS women. Hum Reprod 2015;30(9):2171-7.

28. Chavarro J, Rich-Edwards J, Rosner B, Willett W. A prospective study of dairy foods intake and anovulatory infertility. Hum Reprod 2007;22(5):1340-7. 